\title{
Aoristo)))))
}

International Journal of Phenomenology, Hermeneutics and Metaphysics

\section{Neurolaw between epistemology and ontology: phenomenology and cognitive neurosciences}

\author{
Neurolei entre epistemología e ontología: \\ fenomenología e neurociências cognitivas
}

Prof. PhD. Davide Perrotta

Centro italiano di ricerche fenomenologiche - CIRF'

\begin{abstract}
In the first part of the paper, I present some problematic concepts in cognitive neuroscience, from a philosophical point of view, like causality and Law. These concepts open ontological questions, that we develop proposing a mechanistic interpretation of cognitive neuroscience, compare to a phenomenological investigation of human experience. General descriptions of mental states and intentionality allow us to investigate different forms of causation, not reducible to "material causes". By contrast, cognitive neurosciences are specialized to investigate the latter form, being interpretable both like a bound and an advantage. In the second part of the paper we will resort to the presented epistemological descriptions in order to investigate social cognition. We will discuss the case or moral cognition in order to preserve emergent properties in the human experience, in a complementary way with" cognitive mechanisms". This argumentation will help us to better define the Neurolaw field of researches, allowing us to discern different forms of responsibility of the human acts with regard to different causal factors.
\end{abstract}

\section{KEYWORDS}

Neurolaw; Ontology; Phenomenology; Cognitive neurosciences

\section{RESUMO}

Na primeira parte do artigo, apresento alguns conceitos problemáticos da neurociência cognitiva do ponto de vista filosófico, como causalidade e direito. Esses conceitos abrem questões ontológicas que desenvolvemos propondo uma interpretação mecanicista da neurociência cognitiva, comparadas a uma investigação fenomenológica da experiência humana. Descrições gerais de estados mentais e intencionalidade nos permitem investigar diferentes formas de causalidade, não redutíveis a "causas

\footnotetext{
${ }^{1}$ E-mail: davide.perrotta@hotmail.it, Orcid: https://orcid.org/0000-0001-5426-734X
} 


\section{Aoristo)))))}

International Journal of Phenomenology, Hermeneutics and Metaphysics

materiais". Em contraste, as neurociências cognitivas são especializadas para investigar a última forma, sendo interpretáveis tanto como um limite quanto como uma vantagem. Na segunda parte do artigo, recorreremos às descrições epistemológicas apresentadas para investigar a cognição social. Discutiremos o caso ou cognição moral a fim de preservar propriedades emergentes na experiência humana, de forma complementar com "mecanismos cognitivos". Essa argumentação nos ajudará a definir melhor o campo de pesquisa do Neurolei, permitindo-nos discernir diferentes formas de responsabilidade dos atos humanos em relação a diferentes fatores causais.

\section{PALAVRAS-CHAVE}

Neurolei; Ontologia; Fenomenologia; Neurociências cognitivas

\section{JURIDICAL PHENOMENA AND NATURAL SCIENCE}

In the contemporary debate, several human concepts have been discussed within cognitive neuroscience, such as morality or will. Evidently, the empirical investigations found something peculiar about neural substrates of these human phenomena, but they can doubly be defined anthropological in a strict sense. We are about to maintain a certain form of dichotomist view about human existence, but this strategy will be advocated as a methodological necessity for neurosciences rather than a skeptic position.

Neurosciences, being a scientific field of research, can't be directly involved in anthropological themes, not-natural in the traditional sense, they can, on the contrary, investigate the human being in a naturalistic way, in line with the ontological perspective of natural science. We will maintain a strong identification of the scientific approach with its methodological bound with a certain concept of "causality". Obviously, within the fruitful specializations in philosophy of science (FODOR, 1974), a general interpretation of the methodology of natural science could seem a simplification: anyway, from a phenomenological point of view, this strategy will help us to examine several human phenomena, such as a "crime", that can't be easily explained with a casual account.

Causality can be defined in several senses within different disciplines: regarding physical interactions among molecules or with respect to human actions. In human interactions, we can say "causal" the action that effectively committed a crime, not what preceded it. We are well aware of the juridical definition of "mens rea" and "actus reus" (Goodenough and Tucker 2010): in line with these premises, we have to identify, directly or indirectly, an effective committed action in order to recognize the realization of a crime. In line with jurisprudence, we couldn't just intentionally plan a crime for being "criminals", even thought, intentional planning is considered as a necessary condition for punishment. In this sense, jurisprudence gathers psychological concepts, but we have to ask ourselves if we can define such concepts as "naturalistic" or not (LAVAZZA, DE CARO, 2009).

An epistemological clarification about the two different approach could help us to better explain our opinion about Neurolaw, in order to clarify its field of research, 


\section{Aoristo)))))}

International Journal of Phenomenology, Hermeneutics and Metaphysics

its possibilities to explain human nature and the human crimes or, eventually, to predict the latter.

A discussion on the concept of "cognition" is central to investigate the naturalistic account of neurosciences. I will assume that neurosciences can only mean cognition, or cognitive systems, in a mechanistic way, and this is not a critical view but an epistemological one. If neurosciences can say something about "crimes" or "responsibility" is due to this perspective, how we will discuss.

A difficult issue concerns the defining of neuroscientific researches with their relation between psychological and neural concepts. We will focus our argumentation on cognitive neuroscience, so we are not detailing explaining the traditional cognitive sciences. The philosophical topic about "folk psychology" already well explained some difficulties to give a strict neural account of cognition: we need to precise in which sense we can speak about psychophysiological processes or laws (PUTNAM, 1967; CHURCHLAND, 1989).

\section{WHAT DO WE MEAN WITH “COGNITIVE NEUROSCIENCE”? AN EPISTEMOLOGICAL DISCUSSION}

The concept of "neural substrate" is essential to affirm discoveries about new "cognitive mechanisms", leaving aside if we are treating laws, regularities or tendencies. Without a correlation with neural regularities, we would remain only in a behavioral description or in traditional cognitive science, and we don't mean to detailed discuss the latter approaches. For instance, there is a lot of cognitive researches about mood, personality, and so on, but we need to correlate such psychological "constructs" to a neural reaction in order to define them as "neuroscientific" observations. Both the concepts are paradigmatic in this sense: we can define "mood" or "personality" as a psychological status, empirically detectable with some experimental tools. Following, we can correlate such "dates" with some "dependent variables", like a cognitive performance, but also with a clinical categories, without having the necessity to postulate specific neural states of these complex concepts.

In psychological research, we can define "dependent variables" behavioral parameters, like "milliseconds" needs to respond in a given task or accuracy. Even thought we can find numerous empirical evidences with this methodological strategy, in this paper we will strictly mean a psycophysiological discover when we are in front of a correlation between a psychological construct with a neural substrate, regarding the central nervous system or also peripheral reactions.

Scientific psychology relies its dates on different forms of "probability", a fruitful empirical strategy that excludes the necessity to thoroughly specify which causes are involved in a given statistical distribution. We could say, for instance, that depressed subjects have a major probability to commit a crime, but we can't incriminate such subjects just for this reason. Traits of personality or a clinical status can't be enough to speak about causality and the same goes with a discussion about motivations or 


\section{Aoristo)))))}

International Journal of Phenomenology, Hermeneutics and Metaphysics

reasons. We don't posses information about bi-univocal correspondence among neural substrates and such complex psychological constructs, indeed one speak about "correlations" or similar statistical indices.

Being a biological based science, cognitive neurosciences have the expectation to find stronger empirical dates compare to traditional scientific psychology, requiring the first a more detailed argumentation about causes - rather than probability or tendencies -. For this reason, the psychological lexicon in neuroscience is not directly involved with concepts like personality or mood, but rather with the concept of "cognitive functions". Cognitive psychology can be considered the very lexicon with which we are investigating brain reactions.

With these premises in mind, we need to briefly introduce the modular account that characterizes cognitive psychology. This topic is not just an important philosophical issue (CARRUTHERS, 2006), but an epistemological requirement since the born of neuropsychology (SHALLICE, 1988). Modularity has been for long a difficult proposal to defend, anyway, the contemporary description of "neural networks" is an important innovation to better explain this issue. A given form of cognition can be investigated gathering several neural structures, by maintaining a priority among them, even thought without strong sequentiality. For instance, the ability to "cognitive control" our behaviors preeminently relies on prefrontal cortex, but this is not the only site that participates in such functions (ARON et al. 2014). We need to investigate several neural structures that contribute to inhibitive processes, by including the bottom-up processes that elaborate the stimulus that should be inhibited.

Anyway, cognitive neuroscience possess a difficult ontological account with respect to traditional psychology: concepts like "circuitry", anatomical structures, neurons, aren't obviously psychological and the great deal in the "cognitive ontology" is to find a correlation between a neural vocabulary and a psychological one.

In order to define the epistemological status of a given disciple, we need to investigate this ontological duplicity, being evident the qualitative differences between a "neural architecture" and psychological concepts that characterized our daily life.

\section{NEUROSCIENTIFIC EVIDENCES AND BIOLOGICAL EXPLANATIONS}

The best evidence about the neural architecture and psychological concepts come from Neuropsychology.

This disciple gathers a lot of empirical evidence about spatially localized lesions in correlation with a determined cognitive functioning, in the extended sense of "networks", not just areas.

In order to clarify what neural activities are telling us, we need to specify our interpretation of "cognition" in cognitive neuroscience.

We can anticipate our intention: the strong relation between specific lesion data and determined cognitive functions will be advocated by us in terms of "material 


\section{Aoristo)))))}

International Journal of Phenomenology, Hermeneutics and Metaphysics

causes". This epistemological strategy will be defended in order to understand how neural substrates make possible specific psychological elaborations, meant as the best way to give a naturalistic account of cognition in neurosciences.

Speaking in terms of mechanism means to refer ourselves to causal relations among events or entities, meaning them in a "material" way. Since the Aristotelian physics, we know that there exist different forms of causality and the only one that has been implemented in the scientific research is "material causality" (ALES BELLO, 2017). In my opinion, being neurosciences defined as a science, their epistemological approach necessarily relies on this perspective.

We already premised that a neural network is a complex brain structure: neurotransmitters work on specific brain areas, these areas communicate with others, implementing information or processes. The processing of information must be meant as functional processes allowed by a neural network, the latter defined as a composed circuitry.

A top-down process, high-level in others terms, for instance, is not just a localized cognition, requiring instead several bottom-up processes upon which works.

The Anterior Cingulated Cortex is, for example, one of the best candidates to determine functions to resolve emotive conflicts (BOTVNICK et al. 2004): anyway, in order to achieve this task, we need different emotional processes to be "resolved". We can exclude rigid sequences of neural computations, but we need to maintain the notion of a parallel elaborations of information in order to understand the most complex form of cognition.

We will discuss in this paper how "cognition" can show different forms of causality, being cognitive neuroscience specialized in investigating material causes of it. In order to achieve complex inferences, neuroscientists need to resort to the typical "reductionist" approach of natural science's method. This approach has been for long a critical point for the philosophical traditions and we must make clearer our interpretation of it. Even thought we will argument how the human existence can't be "reduced", if we want to understand it like a "whole", the only way in which we can find scientific discover, laws or regularities about cognitions, is trough reductive strategies.

We can present now a mechanistic view on cognition, in line with concepts like "cognitive mechanism", "cognitive system", as used by neuroscientists, that strongly give us ideas about biological forms of explanation (CRAVER, BECHTEL, 2007; KAPLAN, CRAVER, 2011).

The mechanistic interpretation of the mind-brain system is strongly compared to biological explanations in this paper. In molecular biology, a physiological process like metabolism involves an enormous amount of entities and activities that interact with each other with a hierarchical sequentiality. One of the best methods with which we can analyze a such complex process is to "isolate" its elementary parts, from a micro-organic point of view. Biological explanations are very complex regarding the relation among intra-level or infra-level entities or activities 


\section{Aoristo)))))}

International Journal of Phenomenology, Hermeneutics and Metaphysics

(GALLAGHER, 2018); we won't technically discuss the causal account of a multistrate ontology, for our present scopes revealing such complexity is enough.

Metabolism has a teleological status, an inner finality that we can't totally explain reducing it to its bottom-up mechanism: the best we can do, from a strict scientific perspective, is to discover several mechanisms, properties, entities proteins, enzymes, mitochondrial, and so on - that participate in a such complex highlevel function. Even thought metabolism has a difficult "functional account" to be explained from a pure mechanical point of view, gathering itself "emergent properties" in the physiological level and so on, this doesn't mean that we can't discover several constituents that make it possible. If the metabolism can be meant as a "function", not qualitative explainable by the micro-organic domain, we can nonetheless investigate the micro-organic "mechanism" that could impair it.

The biological modeling approach will be advocated by us as typical of the cognitive neuroscience. Even thought, we will observe how the concept of "function" is much more complex in cognition compared to physiological functions or similar.

Cognitive neurosciences are interested, in my opinion, only in cognitive mechanism, and the concept of "mechanism" along with "cognition" can't explain all the forms of the latter: the human existence is not completely explainable through "isolate functions". Nonetheless, the reductive strategy is an essential step to discover neural substrates of them.

The neuroscience's aim is to discover a mechanism and, this methodological strategy, I repeat, it is not just a narrower explanation: to possess specific understanding about mechanism allow us to manipulate them, to anticipate specific results, to develop clinical treatments. Moreover, only when we are in front of a mechanism, we can relate neuroscientific discovers to Law, developing possible social effects through empirical results

\section{NEUROLAW AND THE HUMAN EXPERIENCE IN AN EPISTEMOLOGICAL DISCUSSION}

The concept of "Law" in Neurolaw shows a difficult account to be defined with the lexicon of "cognitive mechanism". Typically, Law is considered a normative disciple and we know several philosophers claiming that norms don't belong to being (MCDOWELL, 1994). Simplifying, laws can be defined as "cultural" or "juridical" objects, entities of our experience, and within the brain we can't find neither culture nor norms.

Before clarifying our position about Neurolaw, we must explain what we mean with "human experience", the one where we find individual memories as well as cultural manifestations. We will join in this paragraph in the Husserlian approach, the one that, in our opinion, methodologically allows us to better explain the human experience, with its strong relation with a more complex concept of "cognition", encompassing different senses of causality. Once explained a phenomenological description of cognition, we will return to discuss the mechanical components of it. 


\section{Aoristo)))))}

International Journal of Phenomenology, Hermeneutics and Metaphysics

We need to simplify the Husserlian approach in order to relate it, in this paper, to a scientific field. This strategy will help us to discuss complex concepts such "norms", that can be defined only if we go beyond a natural-scientific approach. Being norms historical-collective objects of our experience, they need a different methodology to be understood.

In phenomenology, one speak about "intentionality" to denote the human ability to refer our cognition to different objects of our environment (Husserl 1970). Phenomenological descriptions rely on two important methodological strategies with respect to cognitive neuroscience: a strong attention on "objects" of our cognition the property of our conscious act that we can define "intentionality" -; and the relations between different form of cognition, meant both as main themes to understand the human experience.

We will speak about "experience" in order to precise this field of researches, being "cognition", in neuroscience's meaning, just a specific part of the first. The concept of intentionality must be understood in line with the notion of "phenomenological constitution". To be constitutive, or constituted, is a main technical term in phenomenology, and must be kept distinguish from the metaphysical or scientific sense of it (GALLAGHER, 2018). Constitution in phenomenology possesses an epistemological meaning: we could also say that epistemology led us to ontological researches, but we are not going deeper into this argument. It follows that we can distinguish a constitution of knowledge, in phenomenology, and an ontological constitution, in analytic philosophy or science.

Both the concept, intentionality and constitution, are essential to explain the human experience and we can say that they remain latent - uninvestigated - each time we analyze an individual or groups, also in the empirical researches. Cognitive neuroscience doesn't technically investigate intentionality, in the phenomenological sense. In other terms, If our brain is accustomed to respond to specific stimuli - i.e emotional stimuli or moral ones - we can postulate different past conscious approaches that characterized these peculiar reactions (HUSSERL, 1982).

With strong references to intentional cognition, or "conscious act", intentionality allows us to investigate how our or social experience takes form - is constituted - with the focus to specific objects of our thoughts, or a different sense of interactions with the world. We are introducing these concepts since the difficulty to mean laws as brain entities: we must rather investigate the human relations to laws. Such relation can't be totally understood psychophysiological terms, since laws are not natural objects or events, not perceivable but logically "constituted".

Laws, meant as objects or "essence" of our interactions (HUSSERL, 1990), can be part of the phenomenological investigation by this point of view, being normative rules qualitatively different compare to other objects, like sensorial entities or "rewards". In the philosophical literature, the thesis with which we try to better understand the human dimension advocate the necessity to go beyond just physical entities. Phenomenologists speak about intentionality, Geist or ideality; analytical 


\section{Aoristo)))))}

International Journal of Phenomenology, Hermeneutics and Metaphysics

philosopher about space of reason (MCDOWELL, 1994) or metaphysical conceptions, showing a similar epistemological attitude.

We won't join in technical reconstructions of the Husserlian method, but we have to introduce some typical features of the phenomenological description, without demonstrating them with "Epochè" or similar strategies, as Husserl largely does (ALES BELLO, 2015; ZAHAVI, 2017).

Phenomenology can be examined with different approaches and we will exemplifying the "genetic" form of it. We can speak about a genealogy of experience, or constitution, when we investigate simpler form of human relations to things in order to "discover" the more complex ones. The very sense of "genetic phenomenology" can't be naturalized, given its strong relations to the notion of "experience", in a notnaturalistic-neural way (RAMSTEAD, 2015).

In order to join the phenomenological approach, we must, first of all, investigate the perception, in order to define it carefully. Intentionality is a prominent trait to define perceptive act, since the essential relation to objects in the latter. "Being related to an object" is an epistemological account of phenomenology: we can't investigate the human consciousness beyond the relation between a determined process and its referring object. In this sense, perceptions show an essential peculiarity, their relations with physical-sensorial objects: perceptions manifest perceptive properties of things, like colors, forms, and so on.

The strong attention to "perceptions" was an important epistemological development in the early psychological debates, though which investigate several cognitive processes that cannot be reduced to perceptions or just behaviors. A single perception is temporally bounded and cannot explain alone human environmental reactions: in other terms, we need a series of perceptions to form some representations about the world.

The genetic approach in phenomenology allows us to investigate how the most important concepts of human life take form. The resort to the notion of "perception" is essential in this issue, we "discover" the existence of other forms of cognition, like representations, because, "evidently", perceptions are not able to organize elementary forms of knowledge.

The concept of "discovering" is different to "postulating": often metaphysicians postulate some assumptions that can be following logically investigated. Phenomenology methodologically "discover" conscious processes, being them part of the "human ontology".

Anyway, once postulated or discovered, the knowledge of different forms of cognition allows us to investigate them with different scientific approaches: for instance in animal research. When we empirically investigate representative ability in animals we don't examine how these representations take form, neither their different forms of intentionality, but the several neural reactions that emerged when they are involved in behaviors.

In order to clarify, with the phenomenological description we are not interested in neural substrates, but in the qualitative development of our experience in relation to different cognitions or other forms of acts. In other words, once "discovered" the 


\section{Aoristo)))))}

International Journal of Phenomenology, Hermeneutics and Metaphysics

existence of representations, we won't go to find neural substrates of them, but we will investigate how representation contribute to form the human experience.

Representations show us a different form of "intentionality", a crucial prerequisite of our thought, they are related to not-present objects or state of affairs. On the contrary, perceptions are lacking information and we need to integrate series of perceptions and cognitions in order to elaborate our thoughts about the surrounding world. We can now observe the first occurrences of "different objects" in relation to our cognitions.

\section{DIFFERENT FORM OF CAUSALITY AS ONTOLOGICAL DISCRIMINATION}

In phenomenology, the description of a peculiar object of our experience requires different processes to be explained: by these premises, we can already express some differences with neuroscience.

We can exemplify the ability "to anticipate" events of the world, investigating it trough both epistemological approaches. Anticipative skills can be meant in several senses and, in order to understand this peculiarity, we must remember the phenomenological relation towards objects. In neuroscience, for instance, we can speak about anticipation referring ourselves to "Working Memory", "Planning"; and we will explain how this strategy maintains a mechanistic approach. From a phenomenological perspective, we can distinguish, for instance, anticipation about "properties" of an object or incoming "events". I can see a dog and I can anticipate tactile sensations that I can touch. The representation of a general dog allows me to anticipate some sensorial features. Similarly, but with different phenomenological properties, I can see a knife in my house and I can anticipate that someone wants to kill me. In the latter sense, several "anticipations" are clearly involved, but we must properly speaking about "beliefs", being involved in a very different qualitative description compared to perceptive anticipation. This is one of the simpler cases in which we see a typical intentional reference. To believe is a different act, so possess different intentional properties, that allows me to anticipate events, to be deluded by my wrong anticipation, or to develop social inferences about the external world. In other words, beliefs introduce a strong qualitative development of the human experience.

These types of descriptions aren't only "functional", even thought we could recognize some psychophysiological functions that implement such abilities: how we will discuss, our experience takes form with our iterated interaction with the world.

This brief example introduces us to an important concept in our argumentation, typical also in analytical philosophy. Each time we read sentences about "propositional attitude", "mental states", or similar, we are near the phenomenological description of conscious acts, or Erlebnisse. Several peculiarities of mental states must be defined as the ones that really characterize our experience. In order to simplify, we can maintain the analytical lexicon, speaking about mental 


\section{Aoristo)))))}

International Journal of Phenomenology, Hermeneutics and Metaphysics

states. In line with several analytical philosophers, phenomenology specifies that there are a lot of different mental states (DENNETT, 1978; DAVISON, 1980): belief, desires, judgments, hopes, and so on. Each of them, anyway, can be phenomenological investigated, in order to achieve qualitative descriptions of them and defining their contributions in constituting ours or collective experience. What is important in this paper is the "constitutive" role of mental acts: they are not just cognitions or expressed propositions, they are constituents of human experience, both individual and social.

\section{CAN WE FIND INTENTIONALITY IN COGNITIVE NEUROSCIENCE?}

We already spoke about "working memory", WM, that can be involved - as empirical researches shows - when we anticipate "event" but also when we anticipate some "reward". In this sense, WM seems to be a single process for different objects (CARRUTHERS, 2006).

Qualitatively speaking, investigating intentionality in detail, rewards can't be defined just a simple anticipation of facts, on the contrary, they requires visceral excitations in order to be such that. Anticipation can be considered with perceptive coordinates, but a "reward" needs to be constituted by an emotive source. Even thought we haven't clarified what "reward" is, each stimulus that can be subsumed in this category allows us to infer these descriptions. A sensorial-perceptive object can't be defined a "reward" if I rely my interaction only on sensorial-external information, like colors or smells: the object can't be a reward if I don't emotively respond to it, even just with a simple pleasure. Following, an anticipation of a reward requires a different definition in terms of conscious acts: anticipation about rewards must be implemented by an emotive act, like a desire.

This example should have shown how the relation to objects requires different investigations about our conscious act compared to neuroscience. From a neuroscientic point of view, "Working Memory" or similar executive functions could be, as a hypothesis, the cognitive mechanisms that gather itself different mental states, without specifying which qualitative traits of interaction is involved

Speaking about anticipations, we presumed that both the case exemplified comprises executive functions, but we don't know what form of knowledge is involved in such processes just observing reactions of the nervous system. Working memory gathers itself a great part of executive functions, but this specific function is characterized by a determined neural network. As shown with the example, human thought is characterized by a very large number of qualitative features and the resort to WM cannot explain each form of that. This is one of the best examples of "multiple realization" (FODOR, 1974; KIM, 1992): maybe working memory participates in each form of high-level cognition, but it not explain them in detail.

In order to specify how different forms of human experience can be characterized, we can relate our discussion to some contemporary debates.

Differently from the beginning of the analytical debate, nowadays is common to speak about relations among mental states. In line with Husserl, analytical philosophers 


\section{Aoristo)))))}

\section{International Journal of Phenomenology, Hermeneutics and Metaphysics}

correctly assert a not-physical dimension of these processes. Phenomenologists resort to these premises in order to return to the "things itself", since the epistemological necessity to investigate the things of the life world in relation with our conscious capacities. Within the ontology of neuroscience, at least for now, we can't find neural substrate of relations among mental states and, overall, we can't find detailed descriptions of our interaction with "class of objects" -. We can't investigate specific objects in neural states, as well as we can't define them "genealogy", both regarding cultural contingencies or personal developments. A strong qualitative epistemology doesn't necessarily exclude empirical or neural evidence, but it is important to keep it discerned.

Some cognitive mechanisms - like working memory or generally executive functions - could be involved in the most complex forms of cognitions - as described in phenomenology -, but we need to maintain the concept of "multiple realization" to better understand this relation. We can exemplify the case of "inhibition": this cognitive mechanism is considered one of the most important cognitive functions to control our impulsivity or automatic behaviors. Anyway, if we focus our attention on the objects of our cognition - intentional objects -, we can describe different conscious approaches regarding inhibition. For instance, we can be inhibited by the understanding of a wrong logical rules, by a moral value or by juridical coercion.

In this sense, considering the relation between conscious act and class of objects, we are in line with the philosophical conceptions about the crucial role of mental states, the one that allows us to explain difficult metaphysical issue with respect to natural science like individuality, as well as "free will" or "responsibility" (LAVAZZA, DE CARO, 2009).

Laws of nature must be properly defined as the ones that can be discovered through the epistemological perspective of natural science, with which we can investigate relations of causality among events or entities, and so on. On the contrary, the nexus that we can describe about relation among conscious acts has not physical properties and, so, this type of processes can be defined neither in terms of natural laws nor with a mechanical approach.

With the phenomenological perspective, we can define such processes as "intentional", "motivational" - in the sense of a different form of causality -: likewise, we can speak about reasons, in line with analytical philosophers or juridical debates (MORSE, 2018) ${ }^{2}$. All the above mentioned concept can't be restricted to the scientific methodology, since our impossibility to predict them in a strong way. Consciousness is also related to the "possibilities" of cognition (YOSHIMI, 2011), being natural science instead interested in "being".

We spoke about "human experience" because this concept can't be entirely restricted within the cognitive neuroscience researches. In neuroscience we discover, analyze, elementary cognitive functions, such as memory, attention, inhibition, so:

\footnotetext{
${ }^{2}$ A phenomenologist should not use the concept of "reason" in this sense, but for the present argumentation we can maintain such a term.
} 


\section{Aoristo)))))}

\section{International Journal of Phenomenology, Hermeneutics and Metaphysics}

we are not properly investigating mental states, or conscious acts. The same goes for emotional processing: we don't precisely know neural features of feelings or hopes, neuroscience reveal instead processes that subsumed emotive reactions (PANKSEPP, 1982; DAVIDSON et al. 2000), or cognitive elaboration to resolve emotional conflicts, without thoroughly specify in which form this resolution has been conducted.

For example, let's suppose we have the belief that a dog can bite me if a join in its house. In neuroscience, I could refer this expectation on several cognitive functions, like working memory, planning or semantic memory. The qualitative description of such intention is however more complex in order to explain a behavior. For instance, I should have a representation of a dog, a knowledge about its possible ferocity, a semantic conceptions about "house" or "property", an intention to join the house, and so on. All of these processes are not "isolable" if we want to explain a similar type of behavior, they need a causal sequence.

Moreover, the last description is not enough to understand the motivation of this type of action: maybe I need to join in this house because I desire something within it. A knowledge could, so, motivate a desire, a desire an intention to act, and so on. The casual relation between mental state is not physical, not just psychophysiological, since our incapacity to find a precise neural substrate to these "intentional nexuses".

Now a question could arise: if human experience is so complex, what neurosciences are discovering?

Differently from the motivational explanation of behaviors, with regard to specific intentional states and their relation with others, neuroscience expresses itself to mechanical bounds. When we interpret specific clinical pathologies in a causal way, we are investigating specific parts of a neural network that gathers or elaborates information needed to a specific cognitive function. The material cause of cognitions is strongly related to a neural substrate that implements specific information.

Neuropsychology clearly shows us how different functions can be altered and this premises can reveal how the above mentioned example can differ with several senses. A psychophysiological deficit is not about belief, desire or reasons: for instance, we won't find an individual that doesn't have the ability to create belief, instead we are observing patient that possess misleading beliefs (JASPERS, 1997).

Even thought the qualitative traits of mental states can't be naturally described, there are some clinical cases that evidently show how specific brain networks can impair some cognitive elaborations. We don't know precisely why the brain system has specific localizations of information or functions, but if we mean brain networks as mechanisms we can understand how it can be impaired by "material causes". Neurons are organized in such complex forms of circuits that we cannot anticipate what precisely they will do: anyway, we have a general knowledge about the locality where they implement specific functions. In this sense: we can investigate specific clinical status that allows us to infer how classes of information are "blocked".

We are speaking about "information" because is a typical scientific concept, in line with the mechanical attitude of explanation. For instance, if some enzymes don't share signals with other molecules we could find an impaired physiological function, 


\section{Aoristo)))))}

International Journal of Phenomenology, Hermeneutics and Metaphysics

even thought the "material cause" rely on the micro-organic domain. In this sense, even thought a mechanistic approach is not enough to speak about human motivation or reasons, in the sense of relations of mental states, we can discover the cases in which some material substrates are impaired. We don't know why semantic knowledge is localized in areas such frontal lobes; we don't know why the ability to inhibit actions rely on frontal and pre-frontal areas: anyway, the material status of such a circuitry seems to be essential to the more complex forms of cognitions. If a subject has deficit to semantic ability, he, evidently, possesses an impairment to infer consequences of an action. He could join the house because he doesn't know the concept of "property" and he cannot introspectively reason about the premises we above mentioned.

The intentional sequence of reasons can't be impaired because a patient lost the ability to resort to a specific conscious act: instead conscious act - or, simplifying, our thought abilities - can be impaired by a functional lost of information in the mind-brain system.

In order to clarify: a patient could have a mnemonic deficit, that could impair the ability to anticipate an event; likewise, a patient could have a frontal deficit, that doesn't allow him to inhibit an impulsive action. When a material causes is involved - like a metabolic alteration or a circumscribed lesion - the brain system lost elementary functions. In this case, are the not motivations of the behavior to be impaired: instead individual's inferences are lacking information to correctly implement a planned behavior.

The same argument can be extended and better explained within an emotive account of "motivation". Emotionality is the prominent motivational factors, both in animal reactions or in human ones (DAVIDSON et al., 2000). We already said that human emotionality has strong qualitative features, like when elaborated with feelings or hopes: nonetheless, if a patient has an impairment in the ability to process emotions - in a psychophysiological sense - we don't need to specify if his desires are pathological or not, it couldn't be a specific desire at all. For example, if a person has impairment of the amygdale, we expect that specific emotive states could not be part of individual inferences. Conscious act, as to desire, to feel, to hope lost their emotional charge by a mechanical bound in this case, the one that doesn't allow to express an elaborate a representation with an emotional charge.

\section{MENTAL STATES AND OBJECTS AS A MOTIVATIONAL RELATION}

We need to remember that a neuroscientific discover is meant in this paper as a correlation between psychological predicates and neural substrates: in this sense, we can compare different groups with different belief; we could see that their neural activations are different, and infer that beliefs are the "causes" about such activation. Anyway, a typical neural activation for contextual knowledge relies on frontal and pre-frontal sites, from which we could infer the involvement of working memory, selective attention, semantic memory or inhibition. How you can see, neuroscientific 


\section{Aoristo)))))}

International Journal of Phenomenology, Hermeneutics and Metaphysics

terms just mentioned are qualitatively different from the mental states' vocabulary. Mental states could be implicated in such functions, but we actually can't specify which brain network is involved with them. Anyway, we can presume that neuroscience could, in the future, discover specific substrates for mental states, and not only cognitive functions. Maybe, we should develop further frontal and prefrontal psychophysiological taxonomy, in order to involve desire, belief, hopes, feelings, and so on.

We could further presume that, in the long run, the pre-frontal cortex will be divided into different sub-region, and we will find regions of "hopes", desires, belief, and so on. Now we can ask: it would be sufficient to explain normative behaviors, or at least existential development? I advocate it is not, maybe it could better help us to discover clinical treatments, but not to explain the ontology of human existence.

For instance, we couldn't scientifically explain a behavior motivated by a combination of belief and desire: we need to isolate one function at a time in order to examine it in an empirical way. Moreover, beliefs and desires are related to different objects, so they are not isolated functions. In this sense, even thought the psychophysiological correlates could be further investigated, this wouldn't be sufficient to explain normative behaviors or similar phenomena.

We already spoke about the phenomenological method, with its correlation between act and objects. It should be now clearer that belief or desire are profoundly different with regard to the object aimed. Beliefs about an unpleasant social event are strongly different of beliefs about my own capacities; desire for good food is different from a desire that my scientific theory could be empirically corroborated. The phenomenological method distinguishes between Noesi and Noema: the first is a process, that, simplifying, can show similarities with the neuroscientific approach for instance with "anticipation", how discussed -; Noemata are the objects that take form with regard to a Noesi. In this sense, social or cultural objects can't be just a product of the brain, or nervous system, they are Noemata - or intentional objects -, products of our and collective daily experience. In this epistemological claim, we can recognize the dimension of moral values or juridical norms.

\section{NEUROSCIENCE AND MORALITY, AN ONTOLOGICAL DILEMMA}

Neuroscientific researches about morality open one of the most problematic issue in defining the relation between nature and culture, paradigmatic, in my opinion, to better understand Neurolaw. Morality requires deep idiosyncratic references to be defined, cultural and juridical concepts, nonetheless empirical researches are clearly finding specific "signs" of neural activations when we are in front of such phenomena (BZDOK et al., 2012). Neurosciencies make us infer the presence of some "natural" components of morality, neural processes, and we must precise what "natural" account" they could possess.

In phenomenology, we speak about morality when we find our consciousness in relationship with others, involving our emotionality and a medium knowledge of 


\section{Aoristo)))))}

\section{International Journal of Phenomenology, Hermeneutics and Metaphysics}

uses and customs. In this sense, morality is a very complex concept, not just a faculty or a function, being composed of several processes.

When we join in the field of "social cognition", we need to keep in mind a multi-level cognitive ontology, suggested by the phenomenological approach but, I claim, fruitful also in neuroscience. Bottom up processes, like sensorial or emotional processing, are "constitutive" with respect to high-level operations, particularly when we are investigating interpersonal approaches.

The most fundamental needs to understand social cognition, in neuroscience, are the constructs of "empathy" and "Theory of Mind", ToM, (BLAKEMORE et al., 2004; GALLESE, 2001). Despite the strong qualitative differences of these processes, they also need several bottom-up elaborations upon which intervene. Empathy requires an understanding of mine and others emotional states, Theory of Mind, an understanding of sense of agency, on so on. Moreover, both the processes can be elicited by different form of stimuli: mental states can be, for instance, inferred from expressed propositions, a representation of the personality of my interlocutor, and so on; empathy could require the same processes, but necessarily involves a sensorimotor projections of my bodily reactions with others (ZAHAVI, 2014), a recognition of emotive postures, or similar indices. Some clarifications about how we must interpret these elementary elements of social cognition should help us to better understand morality and juridical behavior.

Both the processes exemplified posses specific neural regularities to characterized them and we have to interpret what neural researches are telling us nowadays. Husserl would speak about "Einfühlung" to mean the ability to attribute mental states to others. In this sense, we can develop a parallel with theory of mind, ToM, that can be considered a high-order function, constituted by different processes. Nonetheless, from a functional point of view, ToM can thus be considered a qualitatively different process with respect to the bottom-up process upon which it works.

We are not discussing if social cognitive abilities should be considered as "modules", but asserting their constitutive needs; with the same pattern, we will advocate how ToM and empathy are constitutive with regard to more complex forms of cognition, like morality or juridical behaviors. We can anticipate that we define the latter concepts not as functions, but as dimensions of the human experience, characterized by emergent properties. This doesn't mean that we cannot investigate such phenomenon with neurosciences, we rather need to say what we are observing.

The phenomenological description is highly bounded with the type of objects we are investigating: objects are not brain's entities, they are encountered by some consciousness, elaborate though different processes and so on. We can extend this discussion with morality, in the sense of reactions to moral values or moral scenes: that can be considered strongly related to our ability to infer other's mental states and, in this sense, a much more complex form of cognition compare to the ascription of mental states or empathy alone. Without conceptions about other's intentionality, beliefs or emotive reactions, we couldn't express a moral judgment: in this sense, 


\section{Aoristo)))))}

International Journal of Phenomenology, Hermeneutics and Metaphysics

morality can be defined as a higher-level element with respect to the theory of mind or empathy.

In phenomenology, a discussion about morality has complex reference to values, use or customs, habits, and on so on. If we don't posses values, personal or collective, we couldn't speak about morality: otherwise, to what are we reacting to? The latter theoretical perspective makes us think that, also in cognitive neuroscience like in phenomenology, morality can't be just a cognitive mechanism that reacts in front of such stimuli but an emergent property of different processes.

In order to investigate the "genealogy" of moral's values, and the same goes with personal scopes or existential projects, a functional lexicon is not enough. There is a lot of researches about "social cognition" that correlates specific experimental stimuli with typical neural activations. In moral computations, for instance, the right Temporo-Parietal Junction is a "region of interest", ROI, for the explanation of these phenomena (BZDOK et al., 2012). This cerebral region is shared with abilities to understand the other's intention, so it could corroborate our composed conception of morality.

In my opinion, the neural activations reflect neither the personal attitudes to morality nor the cultural peculiarities of it: on the contrary, in line with a cognitive ontology, ROIs gather the mechanisms that make possible to recognize a moral scene, to blame it or to act in coherence with a value, so multiple functions and representations.

The concept of values, implicated by to concepts of morality, opens a difficult issue for a psychophysiological explanation. Values can't probably be reduced in a bi-univocal relation with neuronal activity: they rely on concepts developed in the course of our experience, so in the bounding among mental states, in the sense we explained.

From this perspective, we won't describe in neuroscience how values take form, how they are elaborated in a personal or cultural narrative. Nonetheless, if morality implies a requirement of value, the ROI's of morality should involve a representation of values.

\section{REPRESENTATIONS OF VALUES BETWEEN PHENOMENOLOGICAL FEATURES AND BRAIN COMPUTATIONS}

We can further develop our argument: we have already claimed the morality should be considered as emergent properties on cognition and the representation of values could be part of this complexity.

Being values a prerequisite to morality, we can hypothesize that ROIs involved in moral cognition are deputed to "recall", or similar processes, different representations that determine evaluative reactions. However, speaking about a "representation of values" is not an easy task.

In neuroscientific literature are often defined "values" every pleasure interactions (HARE et al., 2008): fruit juice or money, for instance, are both defined values, but we prefer to distinguish these stimuli from many proper values, as moral or existential ones. Sensorial objects, such fruits, offers a direct pleasure, money an 


\section{Aoristo)))))}

International Journal of Phenomenology, Hermeneutics and Metaphysics

indirect one, with which we can obtain different forms of sensorial satisfaction. Our past taste of a given fruit allows us to form a representation of a sensorial satisfaction, that could motivate our future interaction with similar "things". Conceptions about moral values require, on the contrary, past or future inferences about the social effect of our actions, as well as cultural conceptions of a framework of values in a given society, that can even contrast with our personal attitudes. In this sense, values are not just "reward" but complex existential and collective "stimuli" of our experience. The intentionality axiom allows us to investigate our relation with objects with qualitative descriptions and we can easily say that our emotional response in front of a scene that implies a value is very different compare to a sensorial reaction to a good fruit.

We have proposed how values are complex existential objects, with a typical involvement of emotive reactions: now we must claim what we are observing from a neural point of view.

In order to achieve a mechanical explanation of morality, a moral reaction should be considered as a composed of different psychophysiological functions, like the ability to infer other's intentions, or to bound an emotive response to a specific representation of a state of affair. In this sense, morality shouldn't be considered a "cognitive function", but an high-level reaction to the environment that needs some elementary functions making it possible: an emergent property of several cognitive mechanisms.

We already said how phenomenology strongly focuses on our interaction with objects instead of only functions. In this sense: we recognize moral or existential values as composed entities, they need references to the Self, to our personal story or cultural influences. All these experiential concepts can't be considered as functions of the brain, neither of consciousness: they are products of our interaction with the world.

Speaking about representations of values, or representation of rules in a similar sense, opens different issues. In phenomenology, we can offer qualitative descriptions about it, but we don't have enough knowledge of our nervous system to precisely understand these processes. Several trials to describe these forms of representations have been referred to concepts as "neural dispositions" or connectionist models (CHURCHLAND, 1989; YOSHIMI, 2011). Several neuroscientists speak about a widespread of synaptic connections when we need to define how the brain can represent very complex concepts. We can represent ourselves a homicide, but homicide is neither a brain entity nor a function. To represent a homicide needs semantic processes, comprising juridical knowledge, and the same explanation goes with moral values. We don't expect to find a specialized form of memory for values or juridical concepts: they could depend on different forms of codification, emotional, semantic, episodic. When we speak about the elaboration of "percept", in cognitive neuroscience, is typical to divide the brain system in a functional way. Neuroscientific researches about perception are maybe the most famous example with this regard. We know that different parts of visual 


\section{Aoristo)))))}

International Journal of Phenomenology, Hermeneutics and Metaphysics

stimuli are elaborated in different parts of the brain (GOODELE, MILNER, 1992): however, this doesn't mean that our phenomenal experience is "divided". Brain computations are strongly unconscious (SEARLE, 2004; DI FRANCESCO et al., 2018), differently by our daily experience. In this sense, we don't need to postulate a mnestic codification of entities like values: they could be represented by different forms of brain computations.

For instance, I could represent myself a moral scene, but my moral evaluating needs several components to be such that. A sensorial reconstruction of the scene, a projection in other's mental or emotive states, a semantic knowledge of use and customs, an emotional response to the latter processes. In this sense, morality is not specialized functions, but an emergent property of human experience, strongly related to elementary psychophysiological processes that make it possible.

This discussion allows us to propose a thesis: when we investigate several impairments to do a moral evaluation in criminal or clinical populations, we are not investigating just a moral response, but several elementary processes that encompass the prerequisite to this ability. In this sense, a moral impairment could be mechanically caused by different "material causes", in the mind-brain system: it can depend on the impairment of ability to understand other's mental states, or emotive deficits, that impair the elaboration of representations with emotive charges. When there are metabolic alterations, or just lesion to specific neural areas, a subject could not fruit of the most elementary forms of cognitive elaboration: so we can infer the presence of bottom-up mechanisms that impair such existential expression.

Our intention to defend an emergent role human phenomenon like morality or juridical behavior is not a strong bound for neuroscience: in a simpler way, empirical researches should not investigate qualitative features of these phenomena, in an ontological or anthropological sense, but the neural conditions the make them possible, with important development in technology or clinical treatments.

\section{LAWS AND MECHANISMS}

The same argumentation can be extended and better clarified with the topic of juridical behaviors. With the same pattern we used to show the bottom-up relation with the more complex form of morality, we can say that morality itself can be considered as a strong prerequisite of juridical behaviors, but it cannot be the only one (DWORKIN, 1977).

Working on bottom-up processes that make possible such complex existential reactions allows us to infer the existence of material mechanisms responsible for specific neuropsychological impairments.

So, being juridical behavior an emergent properties of different mechanism, we must understand in which sense the latter constitute the first. Therefore, we don't necessarily have to postulate a "module" of juridical behavior, but we could presuppose that specific neural deficits reflect cognitive mechanisms that impair such a form of interpersonal interaction. In this sense, juridical behavior shows an 


\section{Aoristo)))))}

\section{International Journal of Phenomenology, Hermeneutics and Metaphysics}

ontological similarity with morality, but it needs further qualitative traits to be clarified.

We know that the moral sense has a strong motivational account, but we can't define juridical phenomenon only with moral arguments: in this sense, juridical behaviors gather a more complex forms of cognition, maybe the most in the human environment.

The understanding of moral values, or moral scenes, is a crucial prerequisite to juridical evaluations, but not the only one. Subjects with deficit in morality, so in its sub-component how we advocated, could posses enough high-order capacities in order to avoid a legal repression. In this sense, a juridical computation, like the one that allows us to infer social consequences of our actions in relation to specific norms, is not necessarily bounded with emotive reactions, ascription of mental states and so on, but also involves inference processes that allow us to compute social consequences of an action with its juridical effects. With the same but inverse pattern, we could say that a subject with semantic deficits could preserve itself from legal repression relying on moral skills, despite his lacking understanding of the juridical context.

Actually, we don't have detailed reconstruction about neural substrates of a deontological behavior and overall, we don't know where and how juridical rules are codified by the brain. Generally, rules are defined as stored overall in frontal and pre-frontal areas, but these are the same areas the codified rules in general.

Qualitatively speaking, juridical rules are strongly different by some rules involved in resolving a task.

Different forms of interactions need to be better examined in order to develop Neurolaw. Human laws are complex anthropological objects, which are reciprocally constituted. They can be created, modified, and so on, and these existential prerogatives can't rely on pure brain mechanisms. The same goes for "subjective attitudes" with respect to a specific legal system. For instance, I could commit a crime event thought I clearly know its proper immorality, legal consequences, and so on. I could, moreover, commit this crime because I desire to kill a person, and the sequence of mental states do not possess a mechanistic nature, how we explained.

In this sense, we should isolated different cognitive functions that could impair cognitive control in such existential situations. Inhibition or semantic memory are probably the best candidate to argument this thesis: without a conceptual understanding of the normative context of my own community, I couldn't correctly achieve a normative behavior. In the same sense, if a subject possess cognitive impairment with regard to the simplest inhibitive processes, I expect that he couldn't inhibit his behaviors with respect to a juridical norm: nonetheless, a moral inhibition should be provoked by affective projections toward the others, so the same subject could be preserved from punishment.

The researches of material causes are the methodological strategy with which we could effectively discern intellectual or volitional impairments. Neurolaw, it meant as a scientific field (Goodenough and Tucker 2010), can be developed if we discover specific psychophysiological mechanisms that allow us to achieve a 


\section{Aoristo)))))}

International Journal of Phenomenology, Hermeneutics and Metaphysics

deontological behavior. As already shown, the explanation of human behavior requires a detailed reconstruction of individual inferences that motivate an action. If we want to investigate this topic, juridical-deontological requirement should be isolated from different cognitive functions involved in these cognitive abilities, investigating which "cognitive mechanism" could selectively impair the normative behavior, finding several grounding processes for it, as moral reaction, semantic knowledge of the context or the ability to achieve correct logical inferences. If we mean these processes as cognitive mechanisms, as parts of more complex behavioral manifestation, we could find juridical relevant discovers. Only in this case we would be in front of a "mens" that it couldn't be defined "rea", when we are in front of causal, not motivational or intentional, impairments of the brain structures.

We find now the same ontological fractures we discussed before: the only strategy, in my opinion, that really allow us to say something about the possibility to preserve some individuals from crimes or responsibility. On the contrary, the human experience strongly depends on a complex sequence of mental states, subjective feeling or cultural influences, that can't be preserved from punishment when they depend on motivational causes.

\section{CONCLUSION}

Returning on the phenomenological approach, we can say that human relations to norms can show different qualities, we can observe cultural influences, personal attitudes, logical investigations about the rationality of them. All of this aspect are not natural - in epistemological and ontological sense -, they rely on intentional relations to a specific object of our social world, products of our collective experience. On the contrary, neuroscience researches should discover specific functions that make our understanding of laws, or our abilities to conform to them, severely impaired. This is the only sense in which neural alterations go beyond human responsibility, where the individual can't be responsible for an act that he cannot comprehend, meant, inhibit, and so on.

To investigate cognitive functioning in Neurolaw need to "isolate" high-level functions that allow us to prevent social consequences: like logical inferences - with regard to legal articles or constitutional features - as well as a specialized semantic knowledge - not necessarily in the modular sense -. Only with this strategy we could find mechanical functions, as part of a brain network, that can define "condition of possibilities" of human legal responsibility.

Differently from morality, how we explained, the human approach to laws should not necessarily rely on emotive reactions or attributions of mental states. The juridical requirement is to follows laws even if we don't appreciate them. Combining processes like anticipating new juridical development - as in the jurists practices -, desire a different legal system, judge my personal attitude as an example of "justice" - as Socrates did -, are intentional processes, not reducible to a naturalistic account. In the field of reasons, we could go beyond the legal system, elaborate new forms of it, like jurists 


\section{Aoristo)))))}

International Journal of Phenomenology, Hermeneutics and Metaphysics

do with their inferences. Only the latter is the theoretical field in which we can consider themes as the "origins of laws" or the rationality of them.

These ontological argumentations allow us to better explain different form of criminality: the criminal could have a clear representation of juridical norms and social effects, but he could prefer to follow his immoral values. All these existential inferences, or mental states, like preferences or choices, can have a "causal account" but not a "material" one: when we remain on human conscious reasons, or conscious act, we cannot speak about intellectual or volitional impairment, given the conscious, motivated, properties of such phenomena.

\section{REFERENCES}

ALES BELLO, A. The Sense of Things: Toward a Phenomenological Realism. Transl. A. Calcagno. In: Analecta Husserliana. v. CXVIII. Dordrecht: Springer, 2015.

Consciousness and Hyletics in Humans, Animals and Machines. In: Representation and Reality

in Humans, Other Living Organisms and Intelligent Machines. (Ed.) G. Dodig-CRNKOVIC; R. Dordrecht: Springer, 2017, p. 247-260.

ARON, A. R.; ROBBINS, T. W; POLDRACK, R. A. Inhibition and the right inferior frontal cortex: one decade on. In: Cognitive Science. n. 4, v.18 (2014).

BLAKEMORE, S.; WINSTON, J.; FRITH U. Social cognitive neuroscience: where are we heading? In: Cognitive Sciences. n.5, v.8 (2004).

BOTVINICK, M. M.; COHEN, J. D.; CARTER, C. S. Conflict monitoring and anterior cingulated cortex: an update. In: Cognitive Sciences. v.8, n.12 (2004).

BZDOK, D.; SCHLBACH, L.; VOGELEY, K.; SCHNEIDER, K.; LAIRD, A. R.; LANGNER, R.; EICKHOFF, S. B. Parsing the neural correlates of moral cognition: ALE meta-analysis on morality, theory of mind, and empathy. In: Brain Struct Funct. n. 217 (2012), p. 783-796.

CARRUTHERS, P. The architecture of the mind. Oxford: Oxford University Press, 2006.

CHURCHLAND, P. M. A Neurocomputational Perspective: The Nature of Mind and the Structure of Science. Cambridge: MIT Press, 1989.

CRAVER, C. F; BECHTEL, W. Top-down causation without top-down causes. In: Biology and Philosophy. n. 22 (2007), p. 457-563.

DAVIDSON, D. Essays on Events and Actions. Oxford: Clarendon Press, 1980.

DAVIDSON, R. J.; JACKSON, D. C.; KALIN, N. H. Emotion, Plasticity, and Regulation: Perspectives From Affective Neuroscience, Psychological Bulletin, n. 6, v. 126, (2000), p. 890-909.

DENNETT, D. C. Brainstorms, Philosophical Essays on Mind and Psychology. Montgomery: Bradford Books, 1978.

DI FRANCESCO, M.; MARRAFFA, M.; PATERNOSTER, A. The Self and its Defenses: From

Psychodynamics to Cognitive Science. Palgrave: Macmillan, 2018.

DWORKIN, R. Taking Rights Seriously. London: Duckworth, 1977.

FODOR, J. A. Special Sciences (or: The Disunity of Science as a Working Hypothesis). In: Synthese. v. 28, n.2 (1974), p. 97-115.

GALLAGHER, S. New Mechanism and the Enactivist Concept of Constitution. In: The Metaphysics of Consciousness. (Ed.) P. Guta. London: Routledge, 2018, p. 207-220.

GALLESE, V. The shared manifold hypothesis: from mirror neurons to empathy. Journal of Consciousness Studies. v. 8, n. 5-7 (2001), p. 33-50. 


\section{Aoristo)))))}

International Journal of Phenomenology, Hermeneutics and Metaphysics

GOODALE, M. A.; MILNER A. D. Separate Pathways for Perception and Action. In: Neurosciences. v. 15 , n. 1 (1992), p.20-25.

GOODENOUGH, O. R.; TUCKER M. Law and cognitive neuroscience. In: Annu. Rev. Law. Soc. Sci. n. 6, (2010), p. 61-92.

HARE, T. D.; O'DOHERTY, J.; CAMERER, C. F.; SCHULTZ, W.; RANGEL, A. Dissociating the Role of the Orbitofrontal Cortex Striatum in the Computation of Goal Values and Prediction Errors. In: The Journal of Neuroscience, v.28, n.22 (2008), p. 5623-5630.

HUSSERL, E. Logical Investigations. New York: Routledge and K. Paul, Humanities Press, 1970. . Ideas Pertaining to a Pure Phenomenology and to a Phenomenological Philosophy. First Book:

General introduction to Pure Phenomenology. Transl. F. Kersten. The Hague: Martinus Nijhoff, 1982. . Ideas Pertaining to a Pure Phenomenology and to a Phenomenological Philosophy: Second

Book. Studies in the Phenomenology of Constitution. Dordrecht: Kluwer, 1990.

JASPERS, K. General Psychopathology. Transl. J. Hoenig; M. W. Hamilton. Baltimore: Johns Hopkins University Press, 1997.

KAPLAN, D. M.; CRAVER, C. F. The Explanatory Force of Dynamical and Mathematical Models in Neuroscience: A Mechanistic Perspective. In: Philosophy of Science. n.78, (2011), p. 601-627. $\mathrm{KIM}$, J. Multiple Realization and the Metaphysics of Reductio. In: Philosophy and Phenomenological Research. v.LII, n. 1 (1992).

LAVAZZA, A; DE CARO, M. Not so Fast. On Some Bold Neuroscientific Claims Concerning Human Agency. In: Neuroethics, 2009.

MCDOWELL, J. Mind and World. Cambridge: Harvard University Press, 1994.

MORSE, S. J. Neurohype and the Law: A Cautionary Tale. Faculty Scholarship. 2006.

PANKSEEP, J. Toward a general psychobiological theory of emotions. In: Behavioral and Brain Sciences. v.5, n.3 (1982), p. 407-422.

PUTNAM, H. Psychological Predicates. In: Art, Mind, and Religion: Proceedings of the 1965 Oberlin Colloquium in Philosophy. (Ed.) Capitan W. H. and Merril D. D., Pittsburgh: University of Pittsburgh Press, 1967, p. 49-54.

RAMSTEAD, M. J. D. Naturalizing what? Varieties of naturalism and transcendental phenomenology. In: Phenomenology and Cognitive Sciences. v. 14, n.4 (2015), p. 929-71.

SEARLE, J. Mind: A brief introduction. Oxford: Oxford University Press, 2004.

SHALLICE, T. From Neuropsychology to Mental Structures. Cambridge: Cambridge University Press, 1988.

YOSHIMI, J. Phenomenology and connectionism. In: Frontiers in Psychology. n. 2, 2011.

ZAHAVI, D. Self and Other. Exploring Subjectivity, Empathy and Shame. Oxford: Oxford University Press, 2014.

. Husserl's Legacy. Phenomenology, Metaphysics \& Transcendental Philosophy. Oxford: Oxford University Press, 2017.

Submitted: June 04, 2021

Accepted: July 02, 2021

Neurolaw between epistemology and ontology: phenomenology and cognitive neurosciences 